\title{
Editorial
}

\section{Changes in Human Genomics}

I would like to welcome you to the second issue of Volume 5 and also to announce several changes to the Journal including new members of our Editorial Board, the introduction of a new section 'Research Highlights' and, crucially, the introduction of open-access papers.

First and foremost, I am delighted to confirm that the Journal is now accepting submissions for open-access papers. We recognise the importance of open access to experts in the field - and the necessary speed with which work needs to be published - but also that the cost to authors is of course significant. In recognition of this we are offering all authors the opportunity to publish papers on an open-access basis, with full indexing in PubMed, Medline and Chemical Abstracts, at a fee of only US $\$ 750 / £, 500$ to cover production costs. We would be delighted if you would like to submit an open-access paper and would welcome any queries you might have. This opportunity is open to individuals as well as genetics associations, research institutions and universities wishing to publish collections of research papers, review articles and proceedings of meetings in a special issue of the Journal. For further details of the Journal and how to submit open-access papers, please contact me directly at: Vasilis.Vasiliou@ucdenver.edu. You can also find further details at: www.henrystewart.com/hg.aspx.
It is with great pleasure that we welcome Mirella Filocamo, (G. Gaslini Institute, Italy), Tadashi Imanishi (Biomedicinal Information Research Center, Japan), Hidetoshi Inoko (Tokai University School of Medicine, Japan), Poh-San Lai (National University of Singapore, Singapore), George P. Patrinos (University of Patras, Greece) and Sumio Sugano (University of Tokyo, Japan) to our Editorial Board. We also welcome Thomas Schlitt, (King's College London, UK) who is replacing Mike Weale, (King's College London, UK) as the Software Review Editor. Mike remains on the Editorial Board of the Journal and we thank him for all the support he has given to this regular feature.

Finally, this issue sees the first installment of the new regular feature for Human Genomics entitled 'Research Highlights', which collates and reviews some of the most cutting-edge research papers from the field. Robert Scheinman (University of Colorado) is the Editor of this Section. We hope you enjoy it.

Vasilis Vasiliou

Editor, Human Genomics University of Colorado, Denver, CO, USA 